\title{
UNSTABLE FEMORAL FRACTURES TREATED WITH TITANIUM ELASTIC INTRAMEDULLARY NAILS, IN CHILDREN
}

Jamil Faissal Soni ${ }^{1}$, Gisele Schelle ${ }^{2}$, Weverley Valenza ${ }^{2}$, Anna Carolina Pavelec ${ }^{2}$, Camila Deneka Arantes Souza $^{3}$

\section{ABSTRACT}

Objective: To evaluate the indications, epidemiology, associated lesions, complications and prognosis among children with unstable femoral diaphysis fractures who were treated with titanium elastic intramedullary nails. Method: This was a retrospective analysis on 24 patients aged 5-12 years with unstable femoral diaphysis fractures who underwent surgical treatment with elastic titanium intramedullary nails at the Cajuru University Hospital, Curitiba-PR, between April 2002 and March 2008, with a minimum follow-up of 36 months. The epidemiological data, angular deviations, leg shortening and bone consolidation were evaluated. Results: The medical files of 113 cases operated between April 2002 and March 2008 were reassessed. From these, 24 cases of unstable femoral diaphysis fractures treated with elastic titanium intramedullary nails with retrograde insertion were included in the study. There were two bilateral fractures and two exposed fractures. Seven patients were female and 17 were male, and the mean age was 8.3 years. The following were presented at the end of the study: shortening, varus or valgus displacement, final retrocurvatum or antecurvatum of zero, and absence of delayed consolidation or pseudarthrosis. Conclusions: The elastic titanium intramedullary nails were easily placed and removed. We believe that using elastic titanium intramedullary nails is a good option for fixation of unstable femoral fractures in children.

Keywords - Fracture Fixation; Femoral Fractures/complications; Intramedullary; Internal Fixators; Orthopedic Fixation Devices; Titanium; Child

\section{INTRODUCTION}

Femoral diaphysis fractures are caused by highenergy trauma and are among the commonest pediatric traumatic lesions treated by orthopedic surgeons ${ }^{(1-3)}$. In children and adolescents, these fractures present bimodal distribution, with peaks at between two and three years of age $(5.9 / 10,000 /$ year) and at $17-18$ years $(4.2 / 10,000 / \text { year })^{(4)}$. The commonest causes are falls, bicycle and motorcycle accidents, and road accidents ${ }^{(5)}$.

The treatment for these fractures ranges from immediate closed reduction using a plaster cast, traction and a plaster cast later on, to surgical stabilization with intramedullary devices, plates and screws and external fixators ${ }^{(6-8)}$. However, there is still much debate regarding the best treatment for children between the ages of six and 16 years.

Use of plaster after a period of traction is a secure method with few complications. However, it is associated with psychological, social, educational and economic difficulties. Certain complications that are present in surgical methods like external fixation, plates and solid intramedullary nails have led to a search for "ideal" fixation devices for the pediatric population. In this manner, flexible intramedullary nails made of titanium have emerged ${ }^{(3)}$.

Surgical treatment of pediatric femoral fractures was avoided for many years, partly because of its

1 - Head of the Pediatric Orthopedics Group, Orthopedics and Traumatology Clinic, Cajuru University Hospital, Pontifical Catholic University of Paraná (PUC-PR), and Workers' Hospital, Federal University of Paraná (UFPR); Adjunct Professor of Orthopedics, PUC-PR; MSc and PhD in Orthopedics, Curitiba, PR, Brazil.

2 - Attending Physician in the Pediatric Orthopedics Group, Orthopedics and Traumatology Clinic, Cajuru University Hospital, Pontifical Catholic University of Paraná (PUC-PR), and Workers' Hospital, Federal University of Paraná (UFPR), Curitiba, PR, Brazil.

3 - Third-year Resident Physician in the Orthopedics and Traumatology Clinic, Cajuru University Hospital, Pontifical Catholic University of Paraná (PUC-PR), Curitiba, PR, Brazil.

Work performed at Cajuru University Hospital, Pontifical Catholic University of Paraná.

Correspondence: Avenida Silva Jardim 1502, ap. 91, 80250-200 Curitiba, Paraná. E-mail: jamilfsoni@hotmail.com

Work received for publication: December 20, 2011; accepted for publication: March 15, 2012.

The authors declare that there was no conflict of interest in conducting this work 
complications (such as renewed fracturing, scarring and infection) and also because of the belief that overgrowth of the femur would occur and therefore that anatomical reduction might not be favorable ${ }^{(9)}$.

Reynolds demonstrated that fractures of the femur and tibia resulted in accelerated growth of these bones for up to two years, reaching a maximum after three months, with a growth rate up to $38 \%$ greater than in the contralateral limb ${ }^{(3)}$. Several studies have shown accelerated overgrowth may occur following a femoral fracture during childhood ${ }^{(10,11)}$ and that this creates deformity in the limb, which persists until adolescence and the start of adulthood ${ }^{(12)}$.

The complications that have been described in relation to the use of titanium elastic nails in cases of femoral fracture are knee pain at the insertion, protruding nail, nail migration or exit, shortening of the fracture, pseudarthrosis and delayed consolidation $^{(13-15)}$. The complications are classified as major or minor. Major complications are those that require surgical treatment, such as skewed consolidation, delayed consolidation or pseudarthrosis ${ }^{(3,13,16)}$.

Intramedullary titanium elastic nails used to treat femoral diaphysis fractures in children present good results, but the same fractures in older children present greater incidence of complications ${ }^{(17)}$.

The conclusion from many studies is that there are greater numbers of complications among patients over the age of 11 years, obese patients or patients with unstable fracture patterns ${ }^{(13,14,16,17)}$. Fractures are considered to be unstable if they are comminuted or long and oblique, i.e. the length of the fracture is greater than the diameter of the femur at the level of the fracture ${ }^{(15,18)}$.

The aim of the present study was to assess the indications, epidemiology, associated lesions, complications and prognosis in treatments for unstable femoral diaphysis fractures in children, using elastic intramedullary nails made of titanium.

\section{MATERIALS AND METHODS}

Retrospective assessments were made on 113 cases of femoral fractures in children that had been treated surgically using titanium elastic intramedullary nails at Cajuru University Hospital, in Curitiba, PR, between April 2002 and March 2008. This study was approved by the Ethics Committee for Research on Human Beings of the Pontifical Catholic University of Paraná, under report no. 0005267/11.
The inclusion criteria were as follows:

- unstable diaphyseal femoral fractures (comminuted or long and oblique, i.e. the length of the fracture was greater than the diameter of the femur at the level of the fracture $)^{(15,18)}$;

- treated using elastic intramedullary nails made of titanium, with retrograde insertion; and

- minimum follow-up of 36 months.

The exclusion criteria were as follows:

- stable femoral fractures;

- fractures in bones presenting pathological conditions;

- fractures in the metaphyseal region; and

- cases in which the approach chosen was anterograde insertion of the flexible intramedullary nails made of titanium.

In total, 24 fractures in 24 patients were studied. Two patients presented bilateral fractures, but only one of the fractures was unstable in each patient (cases 14 and 24).

Chart 1 presents the population analyzed.

This was a retrospective observational study, in which the medical files were evaluated and the following data were gathered: age, sex, mechanism of the trauma, presence of exposure and side affected.

Chart 1 - Data on the patients.
\begin{tabular}{|c|c|c|c|c|c|}
\hline Case & Sex & Side & Age & Exposure & Trauma mechanism \\
\hline 1 & M & R & 12 & Closed & Run over \\
\hline 2 & M & R & 6 & Closed & Run over \\
\hline 3 & M & L & 8 & Closed & Fall from bike \\
\hline 4 & M & L & 9 & Closed & Fall from height \\
\hline 5 & F & L & 11 & Closed & Car crash \\
\hline 6 & M & R & 12 & Closed & Car crash \\
\hline 7 & M & R & 9 & Exposed & Car crash \\
\hline 8 & M & R & 5 & Closed & Run over \\
\hline 9 & M & R & 9 & Closed & Run over \\
\hline 10 & M & R & 7 & Closed & Run over \\
\hline 11 & F & R & 8 & Closed & Run over \\
\hline 12 & M & R & 6 & Closed & Run over \\
\hline 13 & M & R & 5 & Closed & Car crash \\
\hline 14 & F & R unstable \\
+ L stable & 9 & Exposed & Car crash \\
\hline 15 & M & R & 9 & Closed & Fall from motorcycle \\
\hline 16 & F & R & 7 & Closed & Tripped over \\
\hline 17 & M & R & 12 & Closed & Tripped over \\
\hline 18 & M & R & 8 & Closed & Fall from bike \\
\hline 19 & F & R & 6 & Closed & Run over \\
\hline 20 & M & R & 6 & Closed & Run over \\
\hline 21 & F & L & 9 & Closed & Car crash \\
\hline 22 & M & R & 10 & Closed & Tripped over \\
\hline 23 & F & L & 10 & Closed & Car crash \\
\hline 24 & M & $\begin{array}{c}\text { R unstable } \\
+ \text { L stable }\end{array}$ & 7 & Closed & Car crash \\
\hline
\end{tabular}


The angular deviations were assessed on anteroposterior and lateral radiographs produced before the operation, immediately after the operation, later on after the operation and after removal of the synthesis material (Figure 1). The angular deviations evaluated were valgus, varus, antecurvatum and retrocurvatum.

Shortening or overgrowth was assessed using scanometry or panoramic radiographs of the lower limbs at the end of the treatment.

The criteria of Flynn et $a l^{(1)}$ were developed in order to assess the results relating to use of flexible intramedullary nails and consisted of four criteria: discrepancy between the limbs, deviations, pain and complications. The criteria for determining that the prognosis was poor were discrepancies greater than $2 \mathrm{~cm}$, more than 10 degrees of deviation, pain and major complications and/or elevated morbidity. If a patient presented any of these criteria, the prognosis was considered to be poor $^{(18)}$. Consolidation was evaluated using the abovementioned criteria of Flynn et $a l^{(1)}$ with regard to angular deviation, shortening and bone consolidation.

\section{STATISTICAL METHODOLOGY}

For the statistical analysis, descriptive statistical measurements were calculated with the objective of summarizing the set of data analyzed. Thus, the quantitative variables of the study were characterized by calculating means, standard deviations, minimums and maximums. The categorical variables were summarized by means of frequency tables.

To compare the evaluation times regarding the proportion of cases with null deviation, Fisher's exact test was applied. To compare the assessment times regarding the mean angular deviation, Wilcoxon's test was applied. To investigate the association between age and deviations, Spearman's coefficient was calculated. The association between sex and deviation was investigated by applying the Mann-Whitney test.

\section{RESULTS}

We observed that $70.83 \%$ (17 patients) were male. The maximum age was 12 years and the minimum age was five years (mean of 8.33 years) (Table 1).

Regarding the side affected, $79.17 \%$ of the patients presented a fracture in the right femur and there were two cases of bilateral fracture. In $91.67 \%$ of the patients, the fractures did not present exposure. The trauma mechanisms were high energy, among which $37.5 \%$ consisted of being run over, $29.17 \%$ were falls (from a height, tripping over or from bicycles) and $33.33 \%$ were collisions (Table 2 ).

Regarding shortening, the proportion with zero angular deviation increased significantly from before the operation to the final evaluation $(p=0.0151)$. The mean shortening reduced from 1.61 degrees to 0.39 degrees, which was a significant difference $(p=0.016)$ (Chart 2).

The proportion for which the varus or valgus deviation in the frontal plane was considered to be zero increased significantly from before the operation to the final evaluation $(p=0.0002)$. The mean reduced from 1 to 0 degrees, which was a non-significant difference $(p=0.50)$ (Chart 3).

The proportion for which the antecurvatum or retrocurvatum deviation in the sagittal plane was considered to be zero increased significantly from before the operation to the final evaluation $(p=0.0001)$. The mean reduced from -0.38 degrees to 0 degrees, which was a non-significant difference $(\mathrm{p}=0.94)$ (Chart 4).

There was a significant association between the deviations and age, with shortening in the immediate postoperative period $(p=0.03)$ (Table 3$)$.

There was no significant association between the deviations and sex (Table 4).

The deviations and shortening did not show any significant association with age or sex (Table 5).

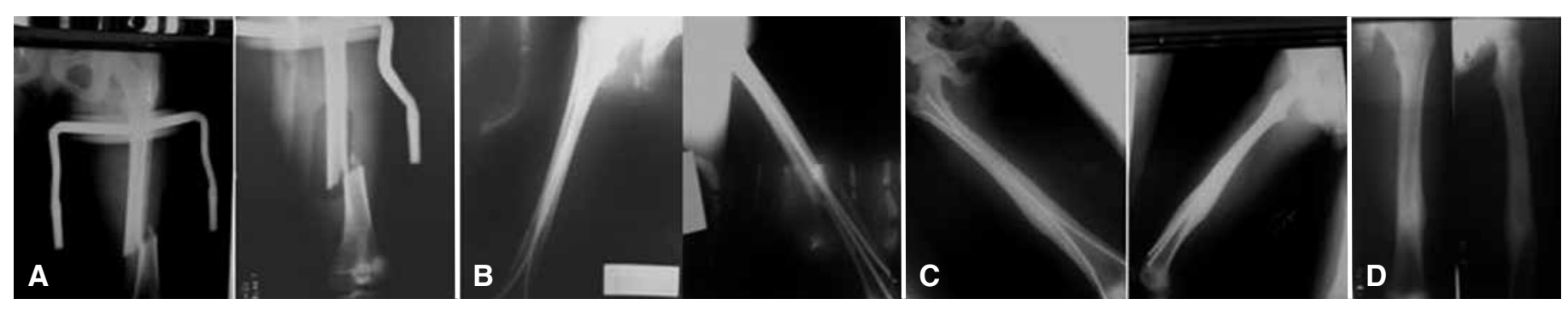

Figure 1 - Series of anteroposterior and lateral radiographs on the femur of a 10-year-old female patient who was a victim in a car crash: before the operation $(A)$, early postoperative period $(B)$, late postoperative period $(C)$ and final postoperative evaluation $(D)$ after removal of the elastic intramedullary nails. Source: SAME HUC PUC-PR. 
Table 1 - Patient distribution according to sex and age.

\begin{tabular}{c|c|c|c|c|c}
\hline \multicolumn{2}{c|}{ Sex } & \multicolumn{2}{c|}{ Frequency } & \multicolumn{2}{c}{ Percentage } \\
\hline \multicolumn{2}{c|}{ Male } & \multicolumn{2}{c|}{17} & \multicolumn{2}{c}{$70.83 \%$} \\
\hline \multicolumn{2}{c|}{ Female } & \multicolumn{2}{c|}{7} & \multicolumn{2}{c}{$29.17 \%$} \\
\hline \multicolumn{2}{c|}{ Total } & \multicolumn{2}{c}{24} & \multicolumn{2}{c}{$100.00 \%$} \\
\hline & Sample & Mean & Minimum & Maximum & $\begin{array}{l}\text { Standard } \\
\text { deviation }\end{array}$ \\
\hline Age & 24 & 8.33 & 5 & 12 & 2.14 \\
\hline
\end{tabular}

Source: SAME HUC PUC-PR.

Table 2 - Patient distribution according to side affected, fracture mechanism and exposure of the fracture.

\begin{tabular}{c|c|c}
\hline Side & Frequency & Percentage \\
\hline Right & 19 & $79.17 \%$ \\
\hline Left & 5 & $20.83 \%$ \\
\hline Total & 24 & $100.00 \%$ \\
\hline Trauma mechanism & Frequency & Percentage \\
\hline Run over & 9 & $37.50 \%$ \\
\hline Fall & 7 & $29.17 \%$ \\
\hline Collision & 8 & $33.33 \%$ \\
\hline Total & 24 & $100 \%$ \\
\hline Exposure & Frequency & Percentage \\
\hline Closed & 22 & $91.67 \%$ \\
\hline Exposed & 2 & $8.33 \%$ \\
\hline Total & 24 & $100 \%$ \\
\hline
\end{tabular}

Fonte: SAME HUC PUC-PR.

Chart 2 - Evaluation of shortening before the operation and in the early postoperative period, late postoperative period and final postoperative evaluation.

\begin{tabular}{|c|c|c|c|c|c|c|c|c|}
\hline \multirow[b]{2}{*}{ Shortening } & \multicolumn{2}{|c|}{$\begin{array}{c}\text { Before } \\
\text { operation }\end{array}$} & \multicolumn{2}{|c|}{$\begin{array}{c}\text { Early } \\
\text { postop }\end{array}$} & \multicolumn{2}{|c|}{ Late postop } & \multicolumn{2}{|r|}{ Final } \\
\hline & $\mathbf{F}$ & $\%$ & $\mathbf{F}$ & $\%$ & $\mathbf{F}$ & $\%$ & $\mathbf{F}$ & $\%$ \\
\hline Same & 4 & $25.00 \%$ & 8 & $33.33 \%$ & 20 & $83.33 \%$ & 15 & $65.22 \%$ \\
\hline$>0$ & 12 & $75.00 \%$ & 16 & $66.67 \%$ & 4 & $16.67 \%$ & 8 & $34.78 \%$ \\
\hline$<0$ & 0 & $0.00 \%$ & 0 & $0.00 \%$ & 0 & $0.00 \%$ & 0 & $0.00 \%$ \\
\hline Sample & 16 & $100.00 \%$ & 24 & $100.00 \%$ & 24 & $100.00 \%$ & 23 & $100.00 \%$ \\
\hline Shortening & & $\begin{array}{l}\text { Before } \\
\text { peration }\end{array}$ & & $\begin{array}{l}\text { Early } \\
\text { oostop }\end{array}$ & Lat & e postop & & Final \\
\hline Mean & & 1.61 & & 1.04 & & 0.4 & & 0.39 \\
\hline Minimum & & 0 & & 0 & & 0 & & 0 \\
\hline Maximum & & 4.2 & & 5 & & 5 & & 2.7 \\
\hline SD & & 1.32 & & 1.18 & & 1.11 & & 0.72 \\
\hline
\end{tabular}

Legend: $\mathrm{F}=$ frequency, $\%$ = percentage, postop = postoperative period, Final = final postoperative evaluation, $\mathrm{sd}=$ standard deviation

Source: SAME HUC PUC-PR.

Chart 3 - Evaluation of the varus and valgus deviations before the operation and in the early postoperative period, late postoperative period and final postoperative evaluation.

\begin{tabular}{|c|c|c|c|c|c|c|c|c|}
\hline \multirow{2}{*}{\begin{tabular}{|l|} 
\\
$\begin{array}{l}\text { Varus / } \\
\text { valgus }\end{array}$ \\
\end{tabular}} & \multicolumn{2}{|c|}{$\begin{array}{c}\text { Before } \\
\text { operation }\end{array}$} & \multicolumn{2}{|c|}{ Early postop } & \multicolumn{2}{|c|}{ Late postop } & \multicolumn{2}{|r|}{ Final } \\
\hline & $\mathbf{F}$ & $\%$ & $\mathbf{F}$ & $\%$ & $\mathbf{F}$ & $\%$ & $F$ & $\%$ \\
\hline Same & 8 & $50.00 \%$ & 15 & $62.50 \%$ & 22 & $91.67 \%$ & 23 & $100.00 \%$ \\
\hline$>0$ & 5 & $31.25 \%$ & 5 & 20.8 & 1 & $4.17 \%$ & 0 & $0.00 \%$ \\
\hline$<0$ & 3 & $18.75 \%$ & 4 & $16.67 \%$ & 1 & $4.17 \%$ & 0 & $0.00 \%$ \\
\hline Sample & 16 & $100.00 \%$ & 24 & $100.00 \%$ & 24 & $100.00 \%$ & 23 & $100.00 \%$ \\
\hline $\begin{array}{l}\text { Varus I } \\
\text { valgus }\end{array}$ & \multicolumn{2}{|c|}{$\begin{array}{c}\text { Before } \\
\text { operation }\end{array}$} & \multicolumn{2}{|c|}{ Early postop } & \multicolumn{2}{|c|}{ Late postop } & \multicolumn{2}{|r|}{ Final } \\
\hline Mean & & 1 & & -0.21 & & -0.29 & & 0 \\
\hline Minimum & & -21 & & -10 & & -10 & & 0 \\
\hline Maximum & & 20 & & 12 & & 3 & & 0 \\
\hline SD & & 9.3 & & 4.71 & & 2.16 & & 0 \\
\hline
\end{tabular}

Legend: $\mathrm{F}$ = frequency, $\%$ = percentage, postop = postoperative period, Final = final postoperative evaluation, $\mathrm{sd}=$ standard deviation.

Source: SAME HUC PUC-PR.
Chart 4 - Evaluation of antecurvatum and retrocurvatum deviations before the operation and in the early postoperative period, late postoperative period and final postoperative evaluation.

\begin{tabular}{|c|c|c|c|c|c|c|c|c|}
\hline \multirow{2}{*}{\begin{tabular}{|c|} 
\\
$\begin{array}{c}\text { Ante I } \\
\text { retro }\end{array}$
\end{tabular}} & \multicolumn{2}{|c|}{$\begin{array}{c}\text { Before } \\
\text { operation }\end{array}$} & \multicolumn{2}{|c|}{ Early postop } & \multicolumn{2}{|c|}{ Late postop } & \multicolumn{2}{|r|}{ Final } \\
\hline & $F$ & $\%$ & $\mathbf{F}$ & $\%$ & $\mathbf{F}$ & $\%$ & $\mathbf{F}$ & $\%$ \\
\hline Same & 7 & $43.75 \%$ & 18 & $75.00 \%$ & 21 & $87.50 \%$ & 23 & $100.00 \%$ \\
\hline$>0$ & 3 & $18.75 \%$ & 4 & $16.67 \%$ & 2 & $8.33 \%$ & 0 & $0.00 \%$ \\
\hline$<0$ & 6 & $37.50 \%$ & 2 & $8.33 \%$ & 1 & $4.17 \%$ & 0 & $0.00 \%$ \\
\hline Sample & 16 & $100.00 \%$ & 24 & $100.00 \%$ & 24 & $100.00 \%$ & 23 & $100.00 \%$ \\
\hline $\begin{array}{l}\text { Ante I } \\
\text { retro }\end{array}$ & \multicolumn{2}{|c|}{$\begin{array}{c}\text { Before } \\
\text { operation }\end{array}$} & \multicolumn{2}{|c|}{ Early postop } & \multicolumn{2}{|c|}{ Late postop } & \multicolumn{2}{|r|}{ Final } \\
\hline Mean & \multicolumn{2}{|r|}{-0.38} & \multicolumn{2}{|r|}{1.96} & \multicolumn{2}{|r|}{0.92} & \multicolumn{2}{|r|}{0} \\
\hline Minimum & \multicolumn{2}{|r|}{-20} & \multicolumn{2}{|r|}{-4} & \multicolumn{2}{|r|}{-4} & \multicolumn{2}{|r|}{0} \\
\hline Maximum & \multicolumn{2}{|r|}{20} & \multicolumn{2}{|r|}{18} & \multicolumn{2}{|r|}{16} & \multicolumn{2}{|r|}{0} \\
\hline SD & \multicolumn{2}{|r|}{9.07} & \multicolumn{2}{|r|}{5.68} & \multicolumn{2}{|r|}{3.91} & \multicolumn{2}{|r|}{0} \\
\hline
\end{tabular}

Legend: $\mathrm{F}=$ frequency, $\%$ = percentage, Ante = antecurvatum, retro = retrocurvatum, postop = postoperative period, Final $=$ final postoperative evaluation, $\mathrm{sd}=$ standard deviation. Source: SAME HUC PUC-PR.

Table 3 - Correlations between age and deviations.

\begin{tabular}{c|c|c|c}
\hline & Sample & Ratio & p-value \\
\hline Pre-short & 16 & -0.21694 & 0.42 \\
\hline Pre-VV & 16 & -0.19511 & 0.47 \\
\hline Pre-AR & 16 & 0.05553 & 0.84 \\
\hline EPO-short & 24 & -0.43923 & 0.03 \\
\hline EPO-VV & 24 & 0.02206 & 0.92 \\
\hline EPO-AR & 24 & -0.37332 & 0.07 \\
\hline PO-short & 24 & -0.17974 & 0.4 \\
\hline PO-VV & 24 & 0.07393 & 0.73 \\
\hline PO-AR & 24 & -0.39462 & 0.06 \\
\hline F-short & 23 & -0.33096 & 0.12 \\
\hline F-VV & 23 & $2.18 \mathrm{E}-10$ & 1 \\
\hline F-AR & 23 & $2.18 \mathrm{E}-10$ & 1
\end{tabular}

Legend: Pre-short $=$ preoperative shortening, Pre-VV = preoperative varus/valgus, Pre-AR = preoperative antecurvatum/retrocurvatum, EPO-short = early postoperative shortening, EPO-VV = early postoperative varus/valgus, EPO-AR = early postoperative antecurvatum/retrocurvatum, $\mathrm{PO}$ short $=$ postoperative shortening, $\mathrm{PO}-\mathrm{VV}=$ postoperative varus/valgus, $\mathrm{PO}-\mathrm{AR}=$ postoperative antecurvatum/retrocurvatum, F-short $=$ final postoperative shortening, $F-V V=$ final postoperative varus/valgus, F-AR = final postoperative antecurvatum/retrocurvatum.

Source: SAME HUC PUC-PR.

Table 4 - Results from correlations between sex and deviations.

\begin{tabular}{c|c}
\hline & p-value \\
\hline Pre-short & 0.43 \\
\hline Pre-VV & 0.54 \\
\hline Pre-AR & 1 \\
\hline EPO-short & 0.59 \\
\hline EPO-VV & 0.59 \\
\hline EPO-AR & 0.28 \\
\hline PO-short & 0.57 \\
\hline PO-VV & 1 \\
\hline PO-AR & 0.82 \\
\hline F-short & 0.84 \\
\hline F-VV & 1 \\
\hline F-AR & 1
\end{tabular}

Legend: Pre-short $=$ preoperative shortening, Pre-VV = preoperative varus/valgus, Pre-AR = preoperative antecurvatum/retrocurvatum, EPO-short = early postoperative shortening, EPO-VV = early postoperative varus/valgus, EPO-AR = early postoperative antecurvatum/retrocurvatum, $\mathrm{PO}$ short = postoperative shortening, $\mathrm{PO}-\mathrm{VV}=$ postoperative varus/valgus, $\mathrm{PO}-\mathrm{AR}=$ postoperative antecurvatum/retrocurvatum, F-short $=$ final postoperative shortening, $F-V V=$ final postoperative varus/valgus, F-AR = final postoperative antecurvatum/retrocurvatum.

Source: SAME HUC PUC-PR. 
Table 5 - Differences in deviations and shortening between before the operation and at the final evaluation, in relation to sex and age.

\begin{tabular}{c|c}
\hline Age & p-value \\
\hline Shortening & 0.36 \\
\hline Varus/valgus & 0.43 \\
\hline Ante/retro & 0.79 \\
\hline Sex & p-value \\
\hline Shortening & 0.75 \\
\hline Varus/valgus & 0.28 \\
\hline Ante/retro & 0.91 \\
\hline
\end{tabular}

Legend: ANTE = antecurvatum, RETRO = retrocurvatum

Source: SAME HUC PUC-PR.

\section{DISCUSSION}

Femoral diaphysis fractures occur frequently in children, but dilemmas still exist regarding the treatment in some cases, depending on the patient's age, fracture pattern, soft-tissue conditions, type of trauma and comorbidities. Surgical treatment enables early mobilization and has become an alternative of interest, especially for children presenting multiple trauma, cranial-encephalic trauma, floating knee, multiple fractures and vascular injuries ${ }^{(3,5,15,19,20)}$, which occur mainly in cases of high-energy trauma.

These fractures in children generally result from high-energy trauma, as observed in the present sample $^{(5)}$. Flexible intramedullary nails are considered to be a safe and minimally invasive method with relatively low complication rates ${ }^{(21)}$. Studies have demonstrated that surgical treatment with flexible intramedullary nails successfully achieves the objective of treating pediatric femoral diaphysis fractures and also enables early mobilization and weight-bearing ${ }^{(5,17)}$.

Flexible intramedullary nails made of titanium provide relative stability, with less injury at the focus, thus favoring bone consolidation. They present an excellent consolidation rate, as demonstrated in our study, and rates of 97 to $100 \%$ can be found in the literature ${ }^{(14,20)}$. The length of hospital stay is short. Few problems are found in removing the synthesis material, and the patients' satisfaction rate is high $^{(5)}$.

Studies have demonstrated complication rates of 33 to $62 \%$, and most of these are soft-tissue alterations at the site of the nail implantation. Thus, these are minor complications that do not require surgical intervention and do not leave sequelae. The commonest of these are pain at the nail insertion site, nail protrusion and nail migration or exit. Most of these complications are due to technical failures: for example, the technical guidelines state that the nail should be a maximum of $1 \mathrm{~cm}$ outside of the bone and should not be angled, so as to avoid protrusion and consequent local irritation ${ }^{(13,14,15,20)}$. Many complications are difficult to assess because of retrospective study designs and incomplete data in the medical files. Anterograde insertion presents a low risk of osteonecrosis of the femoral head or injury to the proximal growth plate of the femur, while retrograde insertion avoids these two sequelae. Therefore, in our clinic, we firstly indicate retrograde insertion and then, exceptionally, anterograde insertion $^{(20)}$.

Several studies have shown that overgrowth may occur after a femoral diaphysis fracture during childhood, and that this may create a discrepancy in the lower limbs that persists until adolescence and young adulthood $^{(5,12)}$. Reynolds suggested that overgrowth occurred because of the increased vascularization needed for consolidation, and not through a compensatory mechanism ${ }^{(22)}$. It has been suggested that cerebral dominance may have a role in this: one study did not present significant shortening and most of the patients were affected on the right side ${ }^{(5)}$. It is unnecessary for the lower limbs to be of precisely equal size, given that at the time of skeletal maturity $40-70 \%$ of the population presents discrepancies. This is greater than $2 \mathrm{~cm}$ in $0.1 \%$ of the population ${ }^{(5)}$.

With regard to assessment of the results from using flexible intramedullary nails, the criteria of Flynn et $a l^{(1)}$ are widely used. However, even though these are considered to be a good system for evaluating surgical treatments on pediatric femoral fractures, they do not take into consideration rotational deviations, which are an important factor in fracture reduction ${ }^{(3)}$.

Sink et $a l^{(15)}$ found that the risk of shortening and angular deviation in the early postoperative period following unplanned surgery was significantly greater with the use of elastic intramedullary nails in cases of femoral fracture that were considered to be unstable. Narayanan et al ${ }^{(23)}$ observed that comminuted fractures that compromised more than $25 \%$ of the femoral diaphysis presented higher rates of pseudarthrosis or delayed union, thus suggesting that the stability should be increased using external fixation ${ }^{(18)}$, thereby protecting the reduction, especially in the sagittal plane, as 
reported by Mani et $a l^{(24)}$. Luhmann et al ${ }^{(13)}$ concluded that fixation of femoral fractures in overweight patients and use of flexible intramedullary nails of smaller diameter were associated with greater sagittal angles, and that the coronal angle was correlated with the size of the nail, with technical failure also involved.

Rathjen et al ${ }^{(25)}$ reported that the complications in cases of unstable fractures of the femoral diaphysis in children treated using flexible femoral nails in their study were similar to the complications in cases of stable fractures.

\section{CONCLUSION}

Most cases of femoral diaphysis fracture occur through high-energy trauma.

We conclude that elastic intramedullary nails made of titanium can be indicated for cases of unstable pediatric femoral diaphysis fracture, with good long-term results presented.

We consider that use of elastic intramedullary nails is a good option for fixation of unstable femoral fractures in children.

\section{REFERENCES}

1. Flynn JM, Skaggs D, Sponseller PD, Ganley TJ, Kay RM, Leitch K. The operative management of pediatric fractures of the lower extremity. J Bone Joint Surg Am. 2002;84:2288-300.

2. Hinton RY, Lincoln A, Crockett MM, Sponseller P, Smith G. Fractures of the femoral shaft in children. Incidence, mechanisms, and sociodemographic risk factors. J Bone Joint Surg Am. 1999;81(4):500-9.

3. Saseendar S, Menon J, Patro, DK. Complications and failures of titanium elastic nailing in pediatric femur fractures Eur J Orthop Surg Traumatol. 2010;20(8):635-44.

4. Hedlund $R$, Lindgren $U$. The incidence of femoral shaft fractures in children and adolescents. J Pediatr Orthop. 1986;6(1):47-50.

5. Mutimer J, Hammett RD, Eldridge JD. Assessing leg length discrepancy following elastic stable intramedullary nailing for paediatric femoral diaphyseal fractures. Arch Orthop Trauma Surg. 2007;127(5):325-30.

6. Flynn JM, Hresko T, Reynolds RA, Blasier RD, Davidson R, Kasser J. Titanium elastic nails for pediatric femur fractures: a multicenter study of early results with analysis of complications. J Pediatr Orthop. 2001;21(1):4-8.

7. Flynn JM, Luedtke LM, Ganley TJ, Dawson J, Davidson RS, Dormans JP, et al. Comparison of titanium elastic nails with traction and a spica cast to treat femoral fractures in children. J Bone Joint Surg Am. 2004;86-A(4):770-7.

8. Khazzam M, Tassone C, Liu XC, Lyon R, Freeto B, Schwab J, et al. Use of flexible intramedullary nail fixation in treating femur fractures in children. Am J Orthop. 2009;38(3):E49-E55.

9. Parsch K. Modern trends in internal fixation of femoral shaft fractures in children. A critical review. J Pediatr Orthop B. 1997;6(2):117-25.

10. Barfod B, Christensen J. Fractures of the femoral shaft in children with special reference to subsequent overgrowth. Acta Chir Scand. 1959;116(3):235-50.

11. Greville NR, Ivins JC. Fractures of the femur in children; an analysis of their effect on the subsequent length of both bones of the lower limb. Am J Surg. 1957;93(3):376-84

12. Edvardsen $P$, Syversen SM. Overgrowth of the femur after fracture of the shaft on childhood. J Bone Joint Surg Br. 1976;58(3):339-42.

13. Luhmann SJ, Schootman M, Schoenecker PL, Dobbs MB, Gordon JE. Complications of titanium elastic nails for pediatric femoral shaft fractures. J Pediatr Orthop. 2003;23(4):443-7.
14. Moroz LA, Launay F, Kocher MS, Newton PO, Frick SL, Sponseller $P D$, et al. Titanium elastic nailing of fractures of the femur in children. Predictors of complications and poor outcome. J Bone Joint Surg Br. 2006;88(10):1361-6.

15. Sink EL, Faro F, Polousky J, Flynn K, Gralla J. Decreased complications of pediatric femur fractures with a change in management. J Pediatr Orthop. 2010;30(7):633-7.

16. Wall EJ, Jain V, Vora V, Mehlman CT, Crawford AH. Complications of titanium and stainless steel elastic nail fixation of pediatric femoral fractures. J Bone Joint Surg Am. 2008;90(6):1305-13.

17. Sink EL, Gralla J, Repine M. Complications of pediatric femur fractures treated with titanium elastic nails: a comparison of fracture types. J Pediatr Orthop. 2005;25(5):577-80.

18. Li Y, Stabile KJ, Shilt JS. Biomechanical analysis of titanium elastic nail fixation in a pediatric femur fracture model. J Pediatr Orthop. 2008;28(8):874-8.

19. Caglar O, Aksoy MC, Yazici M, Surat A. Comparison of compression plate and flexible intramedullary nail fixation in pediatric femoral shaft fractures. J Pediatr Orthop B. 2006;15(3):210-4.

20. Mahar A, Sink E, Faro F, Oka R, Newton PO. Differences in biomechanical stability of femur fracture fixation when using titanium nails of increasing diameter. J Child Orthop. 2007;1(3):211-5.

21. Johnson CW, Carmichael KD, Morris RP, Gilmer B. Biomechanical study of flexible intramedullary nails. J Pediatr Orthop. 2009;29(1):44-8.

22. Reynolds A. Growth changes in fractures long bones. J Bone Joint Surg Br. 1981;68(1):83-8.

23. Narayanan UG, Hyman JE, Wainwright AM, Rang M, Alman BA. Complications of elastic stable intramedullary nail fixation of pediatric femoral fractures, and how to avoid them. J Pediatr Orthop. 2004;24(4):363-9.

24. Mani US, Sabatino CT, Sabharwal S, Svach DJ, Suslak A, Behrens FF. Biomechanical comparison of flexible stainless steel and titanium nails with external fixation using a femur fracture model. J Pediatr Orthop. 2006;26(2):182-7.

25. Rathjen KE, Riccio Al, De La Garza D. Stainless steel flexible intramedullary fixation of unstable femoral shaft fractures in children. J Pediatr Orthop. 2007;27(4):432-41. 